Check for updates

Cite this: Chem. Commun., 2022, 58,3358

Received 2nd December 2021, Accepted 21st January 2022

DOI: $10.1039 / d 1 c c 06786 a$

rsc.li/chemcomm

\section{Reactivities of allenic and olefinic Michael acceptors towards phosphines $\dagger$}

\author{
Feng An, (iD a Harish Jangra, (iD a Yin Wei, (DD ${ }^{b}$ Min Shi, (DD *bc Hendrik Zipse (DD *a and \\ Armin R. Ofial (D) *a
}

The kinetics of the reactions of tributylphosphine with allenic and olefinic Michael acceptors in dichloromethane at $20{ }^{\circ} \mathrm{C}$ was followed by photometric and NMR spectroscopic methods. Combination with DFT-calculated methyl anion affinities revealed the relevance of retroaddition barriers in phosphine-catalysed reactions when mixtures of allenic and olefinic substrates are used.

In 1995, the Lu group discovered (3+2)-cycloadditions, in which $\mathrm{Bu}_{3} \mathrm{P}$ or $\mathrm{Ph}_{3} \mathrm{P}$ are used as Lewis-basic catalysts to furnish cyclopentenes from mixtures of alkyl allenoates and electrondeficient alkenes (Fig. 1). ${ }^{1}$ In recent years, the versatility of $\mathrm{Lu}$ cycloadditions was expanded by the development of several catalytic asymmetric versions, which were also applied to the synthesis of core units of natural products. ${ }^{2}$ Computational and kinetic studies showed that phosphonium-dienolate formation can be considered to be the rate-determining step in the catalytic cycle. $^{2 a, 3}$

The rates of adduct formations, in which only one new bond is formed between an electrophile and a nucleophile, can be discussed in a broader context and beyond the limitations of structurally analogous compound classes when the Mayr-Patz eqn (1) is used. ${ }^{4-7}$ Thus, the nucleophilic reactivity of $R_{3} P$ catalysts in a certain solvent is described by the two parameters $N$ (nucleophilicity) and $s_{\mathrm{N}}$ (susceptibility) in eqn (1). ${ }^{8}$ The reactivities of Michael acceptors are characterised by electrophilicity parameters $E$. It has been shown that once $E, N$ and $s_{\mathrm{N}}$

\footnotetext{
${ }^{a}$ Department Chemie, Ludwig-Maximilians-Universtität München, Butenandtstr. 5-13, München 81377, Germany. E-mail: zipse@cup.uni-muenchen.de, ofial@lmu.de

${ }^{b}$ State Key Laboratory of Organometallic Chemistry, Shanghai Institute of Organic Chemistry, Chinese Academy of Sciences, 354 Fenglin Road, Shanghai 200032, P. R. China.E-mail: mshi@mail.sioc.ac.cn

${ }^{c}$ Key Laboratory for Advanced Materials and Institute of Fine Chemicals, East China University of Science and Technology, 130 MeiLong Road, Shanghai 200237, P. R. China

$\dagger$ Electronic supplementary information (ESI) available: Additional tables and figures, procedures for the synthesis and spectroscopic characterisation of $\mathbf{1}$, product studies, details of the kinetic experiments and DFT calculations. See DOI: 10.1039/d1cc06786a
}

of reaction partners in polar reactions are known the secondorder rate constant $k_{2}$ for adduct formation can be predicted with an accuracy within two orders of magnitude. ${ }^{5,6}$

$$
\log k_{2}\left(20{ }^{\circ} \mathrm{C}\right)=s_{\mathrm{N}}(N+E)
$$

Many of the $\mathrm{R}_{3} \mathrm{P}$-catalysed reactions are performed with mixtures of two competing electrophiles, which are often combined in a way that one of the electrophiles carries an spand the other one an $\mathrm{sp}^{2}$-hybridised carbon as the electrophilic centre. ${ }^{1,2,9}$ In this work, we set out to determine the kinetics of the adduct formation of $\mathrm{R}_{3} \mathrm{P}$ with electron-deficient olefins and a set of alkyl and phenyl allenoates to gain a deeper understanding of the factors that influence the initial step of the related $\mathrm{R}_{3} \mathrm{P}$-catalysed organic reactions. ${ }^{1,2,9}$

First, we characterised the vinyl phosphonium triflates 3 obtained by $\mathrm{Ph}_{3} \mathrm{P}$ reactions with 1a, 1d, 1f, and 1i (Fig. 2A) by spectroscopic methods ( $\mathrm{ESI} \dagger$ ). It is reasonable to assume that the entire set of $\mathrm{R}_{3} \mathrm{P}+\mathbf{1 a}-\mathbf{1} \mathbf{j}$ reactions that we followed kinetically also yield vinyl phosphonium triflates 3 . The kinetics of the carbon-phosphorus bond-formations between $\mathrm{R}_{3} \mathrm{P}$ and $\mathbf{1 a}-\mathbf{1 j}$ was followed by spectroscopic methods.

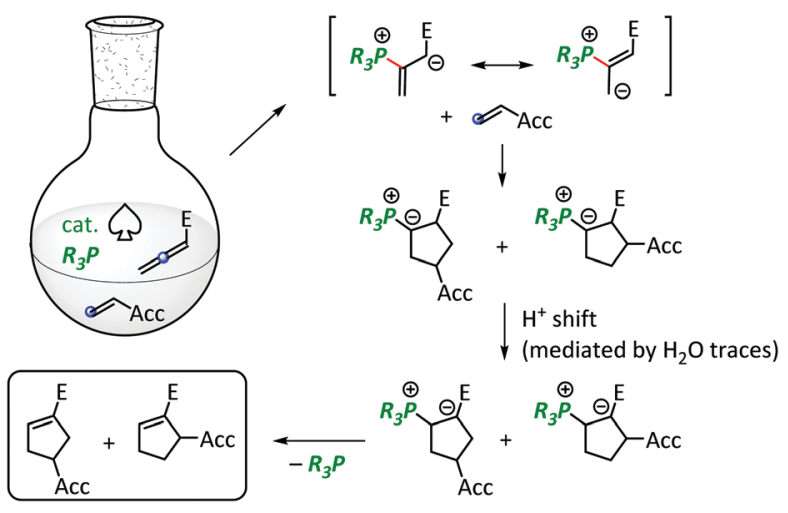

Fig. 1 Mechanism of the phosphine-catalysed Lu cycloaddition ( $E$ = ester group, Acc = electron-accepting group). 


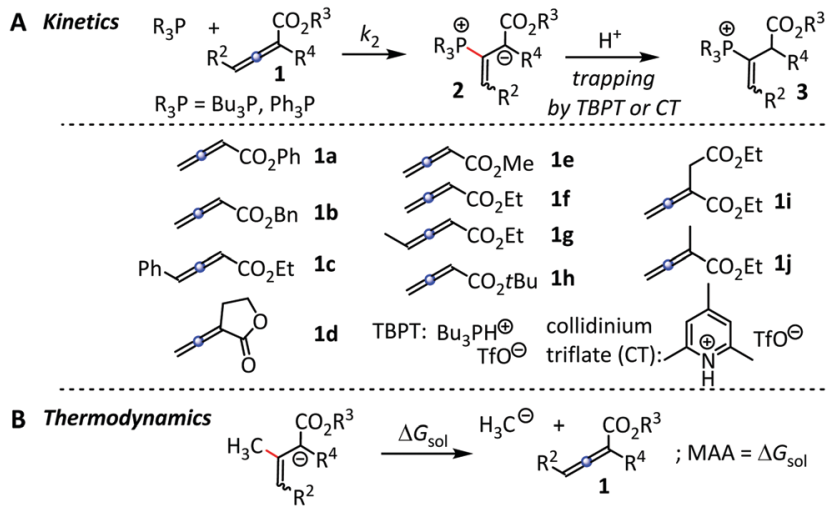

Fig. 2 (A) $\mathrm{R}_{3} P$ additions to 1 and (B) reference reaction for the determination of methyl anion affinities (MAA) by quantum-chemical methods.

Reactions of $\mathrm{Bu}_{3} \mathrm{P}$ with alkyl allenoates $\mathbf{1 a}-\mathbf{1 i}$ in $\mathrm{CH}_{2} \mathrm{Cl}_{2}$ at $20{ }^{\circ} \mathrm{C}$ were monitored photometrically by following the decrease of the UV absorptions of $\mathbf{1}$ at or close to their absorption maximum $\left(\lambda_{\max }=242-262 \mathrm{~nm}\right)$. The $\mathrm{Bu}_{3} \mathrm{P}$ addition reactions to 1 give rise to polymerisation, which can be avoided by trapping the zwitterionic adducts 2 with tributylphosphonium triflate (TBPT) as the proton source $\left([\mathrm{TBPT}] /[\mathbf{1}]_{0}=2-3\right)$. TBPT is a weak Brønsted acid in $\mathrm{CH}_{2} \mathrm{Cl}_{2}$ and does not activate the electrophiles $\mathbf{1}$ by hydrogen-bonding to an oxygen of the ester group (as shown for the combination of $\mathbf{1 f}+$ TBPT, ESI, $\dagger$ Fig. S7). To simplify the kinetic evaluation of the second-order reactions, we used the $\mathrm{Bu}_{3} \mathrm{P}$ in at least 10 -fold excess relative to the initial electrophile concentrations $[\mathbf{1}]_{0}$. Hence, the decrease of absorptions $A$ of $\mathbf{1}$ could be fitted by the mono-exponential decay function $A=A_{0} \exp \left(-k_{\mathrm{obs}} t\right)+C$ to determine the (pseudo) first-order rate constants $k_{\mathrm{obs}}\left(\mathrm{s}^{-1}\right)$.

For each $\mathrm{Bu}_{3} \mathrm{P}+\mathbf{1}$ pair, $k_{\text {obs }}$ was determined at four or five different $\mathrm{Bu}_{3} \mathrm{P}$ concentrations, which made it possible to calculate the second-order rate constants $k_{2}\left(\mathrm{M}^{-1} \mathrm{~s}^{-1}\right)$ from the slope of the linear correlation of $k_{\mathrm{obs}}$ with $\left[\mathrm{Bu}_{3} \mathrm{P}\right]_{0}$. Fig. 3 visualises this procedure for the $\mathrm{Bu}_{3} \mathrm{P}$ addition to $\mathbf{1 f}$.

Rate constants of the reactions of $\mathrm{Ph}_{3} \mathrm{P}$ with $\mathbf{1 a}-\mathbf{1 j}$ were determined by ${ }^{1} \mathrm{H}$ NMR spectroscopy using mesitylene as an internal integration standard and collidinium triflate (CT) as a proton source $\left([\mathrm{CT}] /[\mathbf{1}]_{0}=2\right)$. Generally, $\mathrm{Ph}_{3} \mathrm{P}$ additions to $\mathbf{1}$ are endergonic with retroadditions being faster than the addition reactions. Trapping of the zwitterionic intermediates 2 by CT is thus necessary to observe the kinetics of the addition (forward)
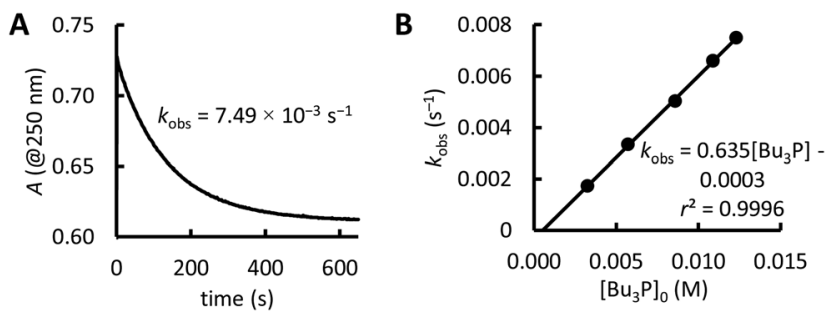

Fig. 3 (A) Kinetics of the reaction of $\mathrm{Bu}_{3} \mathrm{P}$ with 1f: mono-exponential decay of the absorbance $A$ in the reaction of $\mathrm{Bu}_{3} \mathrm{P}(12.3 \mathrm{mM})$ with $\mathbf{1 f}(0.121 \mathrm{mM})$; (B) linear correlation of observed rate constants $k_{\text {obs }}$ with $\left[\mathrm{Bu}_{3} \mathrm{P}\right]_{0}$.
Table 1 Second-order rate constants $\left(k_{2}\right.$, in $\left.\mathrm{M}^{-1} \mathrm{~s}^{-1}\right)$ for the additions of $\mathrm{Bu}_{3} \mathrm{P}$ and $\mathrm{Ph}_{3} \mathrm{P}$ to phenyl or alkyl allenoates 1 in dichloromethane at $20^{\circ} \mathrm{C}$

\begin{tabular}{lllll}
\hline Electrophiles $\mathbf{1}$ & $k_{2}\left(\mathrm{Bu}_{3} \mathrm{P}\right)^{a}$ & $k_{2}\left(\mathrm{Ph}_{3} \mathrm{P}\right)^{b}$ & $\mathrm{MAA}^{c}$ & $\mathrm{PA}^{d}$ \\
\hline $\mathbf{1 a}$ & 5.52 & $1.19 \times 10^{-1}$ & $182.5^{e}$ & -15.0 \\
$\mathbf{1 b}$ & 1.16 & $1.70 \times 10^{-2}$ & $163.1^{e}$ & -22.6 \\
$\mathbf{1 c}$ & 1.10 & $1.90 \times 10^{-2}$ & 165.5 & -23.7 \\
$\mathbf{1 d}$ & $9.55 \times 10^{-1}$ & $2.33 \times 10^{-2}$ & 171.2 & -15.9 \\
$\mathbf{1 e}$ & $8.40 \times 10^{-1}$ & $1.10 \times 10^{-2}$ & $167.6^{e}$ & -26.5 \\
$\mathbf{1 f}$ & $6.35 \times 10^{-1}$ & $7.67 \times 10^{-3}$ & $163.4^{e}$ & -29.8 \\
$\mathbf{1 g}$ & $5.00 \times 10^{-1}$ & $8.05 \times 10^{-3}$ & 152.7 & -29.5 \\
$\mathbf{1 h}$ & $2.47 \times 10^{-1}$ & $2.39 \times 10^{-3}$ & 153.9 & -33.3 \\
$\mathbf{1 i}$ & $2.01 \times 10^{-1}$ & $4.59 \times 10^{-3}$ & 142.5 & -26.0 \\
$\mathbf{1 j}$ & $1.96 \times 10^{-2 b}$ & $3.49 \times 10^{-4}$ & 133.6 & -38.3
\end{tabular}

${ }^{a}$ Photometry, $\mathrm{CH}_{2} \mathrm{Cl}_{2}, 20{ }^{\circ} \mathrm{C} .{ }^{b}{ }^{1} \mathrm{H}$ NMR spectroscopy, $\mathrm{CD}_{2} \mathrm{Cl}_{2}, 20{ }^{\circ} \mathrm{C}$. ${ }^{c}$ MAA as defined in Fig. 2B [in $\mathrm{kJ} \mathrm{mol}^{-1}$ at SMD(DMSO)/B3LYP/6$311++\mathrm{G}(3 \mathrm{df}, 2 \mathrm{pd}) / / \mathrm{B} 3 \mathrm{LYP} / 6-31 \mathrm{G}(\mathrm{d}, \mathrm{p})$ level of theory, with Truhlar quasiharmonic treatment]. ${ }^{d}$ Phosphine affinities, PA, as defined in ESI, Table S42 [in kJ mol ${ }^{-1}$ at PCM(DCM,ua0)/B3LYP-D3/6-31+G(d,p) level of theory, with Truhlar quasi-harmonic treatment]. ${ }^{e}$ MAA values from ref. 10 .

reaction. By obeying the conditions for (pseudo)first-order kinetics, that is $\left[\mathrm{Ph}_{3} \mathrm{P}\right]_{0} /[\mathbf{1}]_{0}>9$, the time-dependent decrease of [1] could be fitted by the mono-exponential decay function to yield the rate constants $k_{\text {obs }}$. NMR experiments at four different $\left[\mathrm{Ph}_{3} \mathrm{P}\right]_{0}$ made it possible to determine the second-order rate constants $k_{2}$ for the $\mathrm{Ph}_{3} \mathrm{P}$ additions to the electrophiles $\mathbf{1 a}-\mathbf{1 j}$ from the slope of the linear correlation of $k_{\mathrm{obs}}$ with $\left[\mathrm{Ph}_{3} \mathrm{P}\right]_{0}$. Rate constants $\left(k_{2}\right)$ for the reactions of $\mathrm{Bu}_{3} \mathrm{P}$ with $\mathbf{1} \mathbf{j}$ were determined analogously. Data of the individual kinetic measurements for the nucleophilic attack of $\mathrm{Bu}_{3} \mathrm{P}$ and $\mathrm{Ph}_{3} \mathrm{P}$ at the allenoates $\mathbf{1}$ are given in the ESI. $\dagger$ The experimentally determined second-order rate constants $k_{2}$ are compiled in Table 1 .

The $\mathrm{Bu}_{3} \mathrm{P}$-based reactivity scale $\left(\log k_{2}\right)$ for $\mathbf{1 a} \mathbf{- 1} \mathbf{j}$ is depicted in Fig. 4A. The phenyl ester $1 \mathbf{a}$ is the strongest electrophile of the studied allenoates without further substituents at the cumulated $\pi$-system and reacts about 5 to 9 times faster with $\mathrm{Bu}_{3} \mathrm{P}$ than the analogous benzyl (1) $)$, methyl (1e), or ethyl esters (1f). ${ }^{11}$ Replacement of the ethyl by a $t$-butyl group $(\mathbf{1 f} \rightarrow \mathbf{1 h})$ attenuates reactivity by a factor of 3 . An additional methyl

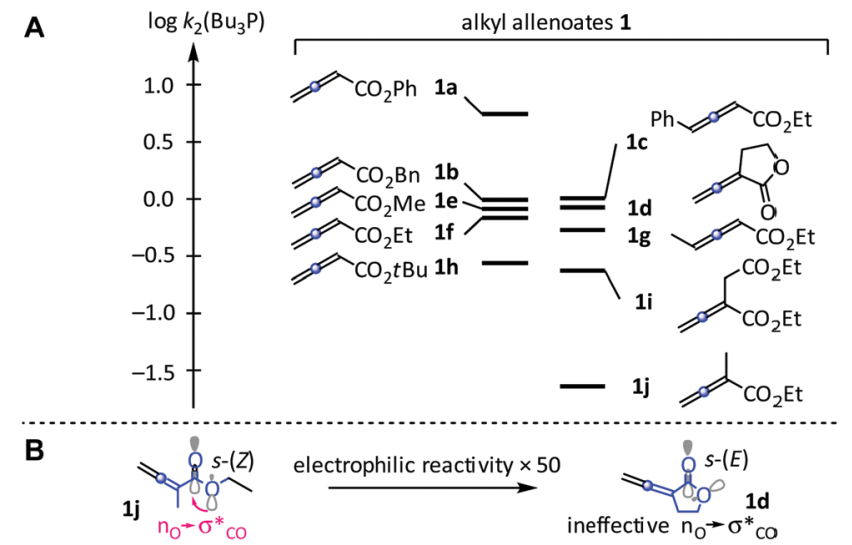

Fig. 4 (A) Relative reactivities of $1 \mathbf{a}-\mathbf{1 j}$ in reactions with $\mathrm{Bu}_{3} \mathrm{P}$ (in $\mathrm{CH}_{2} \mathrm{Cl}_{2}$, $20{ }^{\circ} \mathrm{C}$ ). (B) Different stereoelectronic effects in $\mathbf{1 d}$ and the open-chain analogue $\mathbf{1 j}$. 
group (19) at the 4-position of the alkyl allenoate has almost no influence on the reactivity of the electrophilic $\pi$-system, which remains at the level of the $\gamma$-unsubstituted 1f. Extending the $\pi$-system by a terminal phenyl group enhances the reactivity of 1c only slightly if compared to that of 1f, probably because the phenylvinyl moiety in 1c is perpendicular to the reactive $\pi$-system. In contrast, substituents in 2-position of $\mathbf{1}$ have a greater effect, and $\mathrm{Bu}_{3} \mathrm{P}$ reacts slower by a factor of 32 with $\mathbf{1 j}$ than with the parent 1f. This reactivity gap can be reduced by attaching an electron-accepting group to the C-2 substituent. Thus, $\mathbf{1 i}$ reacts 10 -fold faster with $\mathrm{Bu}_{3} \mathrm{P}$ than $\mathbf{1 j}$ and is only 3 times less electrophilic (towards $\mathrm{Bu}_{3} \mathrm{P}$ ) than $\mathbf{1 f}$.

Consistent with previous work on the relative reactivity of open chain esters and lactones, ${ }^{12} \alpha$-allenic $\gamma$-butyrolactone $\mathbf{1 d}$ is a significantly more reactive electrophile than $\mathbf{1} \mathbf{j}$. The increase in electrophilic reactivity is explained by the different conformations of the CO-OR bonds, which is preferably in the $s$ - $(Z)$ conformation in $\mathbf{1 j}$ but fixed in the unfavourable $s-(E)$ conformation in $1 \mathrm{~d}$ (Fig. 4B). ${ }^{12,13}$ Ineffective $\mathrm{n}_{\mathrm{O}} \rightarrow \sigma^{*}$ CO interactions enhance the electron-deficiency of the reacting $\pi$-system, which enables the versatile use of allenic lactones in organic synthesis. ${ }^{14}$

Reactivity of 1 towards $\mathrm{Bu}_{3} \mathrm{P}$ is transferrable to other $\mathrm{R}_{3} \mathrm{P}$ as shown by the linear correlation $\left(r^{2}=0.9636, n=10\right)$ with a slope (1.02) close to unity for the $\mathrm{Ph}_{3} \mathrm{P} v$ s. $\mathrm{Bu}_{3} \mathrm{P}$ comparison (Fig. 5).

To gain a better understanding of $\mathrm{R}_{3} \mathrm{P}$-catalysed $\mathrm{Lu}$ reactions it is crucial to compare the $\mathrm{R}_{3} \mathrm{P}$ reactivities of $\mathbf{1}$ with those of competing electrophiles, which are typically olefinic Michael acceptors. It was previously shown that MAAs of olefinic Michael acceptors correlate linearly with their Mayr $E$ parameters. ${ }^{15}$ MAA values have also been applied to rationalise $\mathrm{R}_{3} \mathrm{P}$-catalysed $(3+2)$ annulations of $\mathbf{1 a}, \mathbf{1 b}, \mathbf{1 e}$, and $\mathbf{1 f}$ with 2-aminoacrylates. ${ }^{10}$ The data in Table 1 now show that the DFT-calculated MAA values for $\mathbf{1}$ (Table 1) are linearly related with their electrophilic reactivities towards the investigated $R_{3} P$ nucleophiles, that is, $\mathrm{Bu}_{3} \mathrm{P}$ and $\mathrm{Ph}_{3} \mathrm{P}$ (ESI, $\dagger$ Fig. $\mathrm{S} 1$ and $\mathrm{S} 2$ ). A linear correlation of similar quality was obtained when $\log k_{2}$ for $\mathbf{1}+\mathrm{Ph}_{3} \mathrm{P}$ reactions were plotted against phosphine affinities, $\mathrm{PA}$, which are defined analogously to MAA but use $\mathrm{Ph}_{3} \mathrm{P}$ instead of the methyl anion as the Lewis base (Fig. S3, ESI $\dagger$ ).

The nucleophilic reactivity of $\mathrm{Bu}_{3} \mathrm{P}$ has previously been characterised by $N=15.49\left(s_{\mathrm{N}}=0.69\right)$ on the basis of the kinetics of its additions to benzhydrylium ions $(E>-10.04) .{ }^{16}$ To avoid

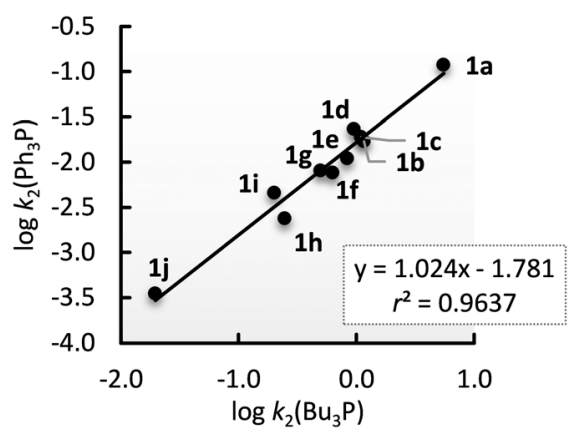

Fig. 5 Linear relation of $\log k_{2}\left(\mathrm{Bu}_{3} \mathrm{P}\right)$ and $\log k_{2}\left(\mathrm{Ph}_{3} \mathrm{P}\right)$ for reactions with 1.

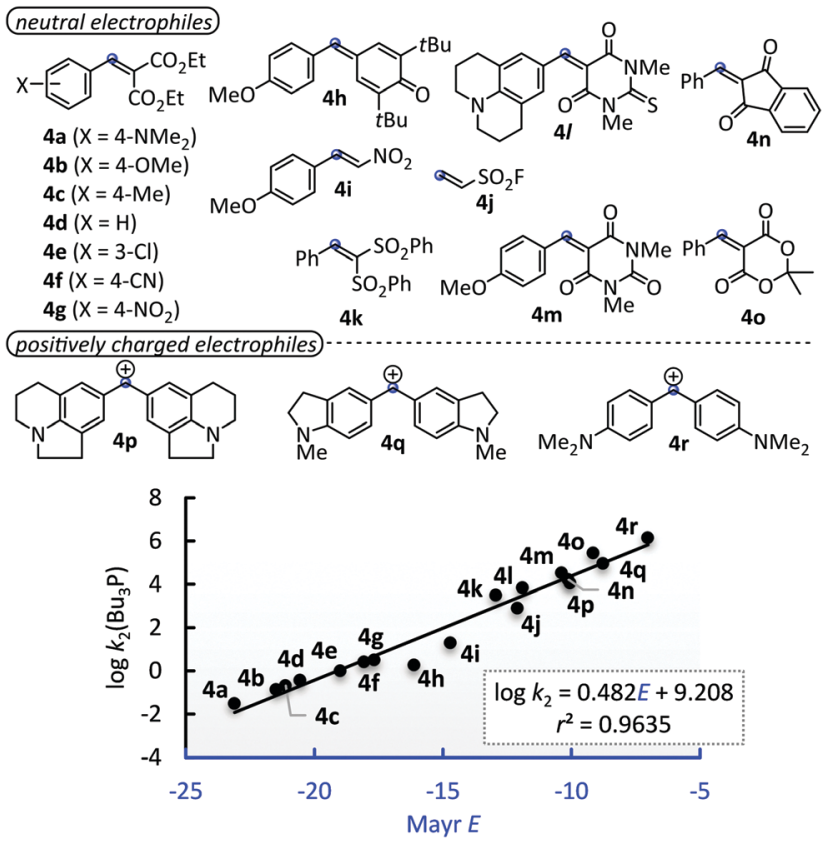

Fig. 6 Linear correlation of $\log k_{2}\left(B u_{3} P\right)$ with the Mayr $E$ parameters of structurally diverse Michael acceptors $4 a-0$ and benzhydrylium ions $4 p-r$ $\left(k_{2}\right.$ in dichloromethane at $20{ }^{\circ} \mathrm{C}$, see $\mathrm{ESI} \dagger$ for details of the kinetic measurements, Table S1 (ESI $\dagger)$ gathers the data used to construct the correlation).

long range extrapolations for predicting reaction rates with Michael acceptors, we determined the kinetics of further reactions of $\mathrm{Bu}_{3} \mathrm{P}$ with the structurally diverse neutral and positively charged electrophiles 4a-4r of known Mayr E. ${ }^{7}$ Second-order rate constants $k_{2}\left(\mathrm{CH}_{2} \mathrm{Cl}_{2}, 20{ }^{\circ} \mathrm{C}\right)$ were determined by applying the photometric methods described above for the $1+\mathrm{Bu}_{3} \mathrm{P}$ reactions (see ESI $\dagger$ for individual rate constants). Fig. 6 shows that $\log k_{2}$ for the additions of $\mathrm{Bu}_{3} \mathrm{P}$ to $\mathbf{4 a}-\mathbf{4 r}$ follow a linear correlation $\left(r^{2}=\right.$ $0.9635, n=18$ ) over a range of 16 units on the Mayr $E$ scale, which gives $N\left(\mathrm{Bu}_{3} \mathrm{P}\right)=19.11$ and $s_{\mathrm{N}}=0.48$. Applying the $k_{2}$ values for reactions of 1 (Table 1 ) in the correlation depicted in Fig. 6 indicates that $\mathbf{1 a}-\mathbf{1} \mathbf{j}$ are located in the reactivity range $-22.7<$ $E<-17.5$.

In classical $\mathrm{Lu}$ reactions, the $\mathrm{R}_{3} \mathrm{P}$ catalyst first attacks the alkyl allenoate. The catalytic cycle continues with the reaction of a C-nucleophilic zwitterion with the second Michael acceptor in the reaction mixture. If the kinetics of the $\mathrm{R}_{3} \mathrm{P}$ reactions with the two competing electrophiles would be the decisive factor, $\mathrm{Lu}$ reactions could be expected to occur only if $\mathbf{1}$ is more reactive towards the $\mathrm{R}_{3} \mathrm{P}$ catalyst than the competing Michael acceptor (e.g., 4). This is not always the case, however. Already in the first publication on the $\mathrm{R}_{3} \mathrm{P}$-catalysed cycloaddition, the Lu group ${ }^{1}$ used electrophiles with Mayr $E<-16.8$, that is, with comparable or even slightly higher electrophilicity than for $\mathbf{1}$. This indicates that the thermodynamics for $\mathrm{R}_{3} \mathrm{P}$ adduct formation is another crucial factor for the success of Lu reactions.

For reactions of vinyl cations with nucleophiles it has been observed that $\mathrm{sp} / \mathrm{sp}^{2}$ rehybridisation occurs via higher Marcus intrinsic barriers than for reactions that involve $\mathrm{sp}^{2} / \mathrm{sp}^{3}$ 


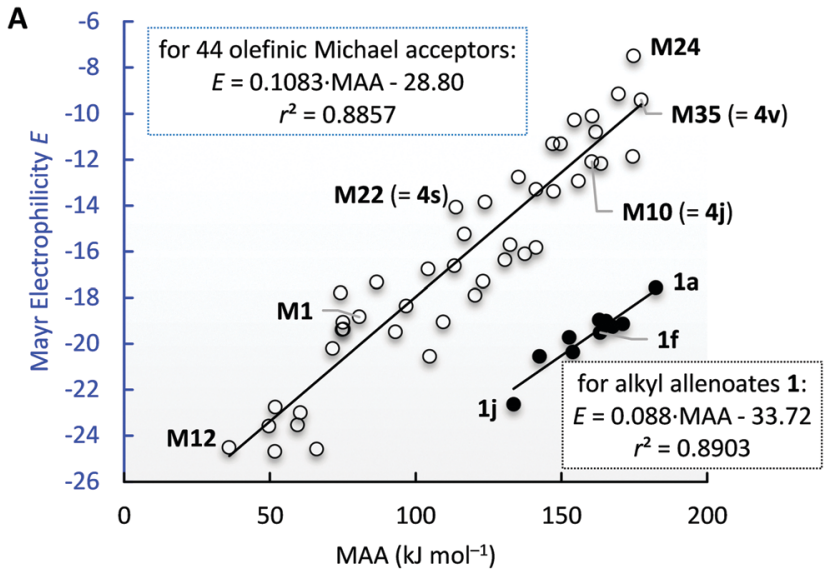

B

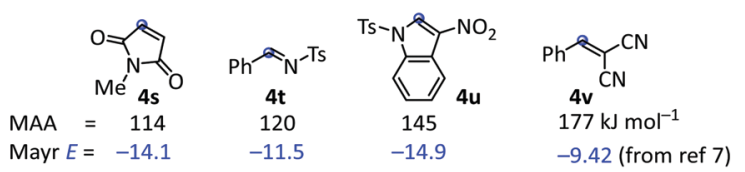

Fig. 7 (A) Separate linear relationships between the electrophilicities $E$ of acceptor-substituted olefins M1-M44 and allenes 1 with the calculated methyl anion affinities (MAA) (molecular structures of M1-M44 and data used to construct the linear correlation are given in ESI, $\dagger$ Table S2; electrophilicities $E$ for allenoates 1 estimated by applying the $k_{2}\left(\mathrm{Bu}_{3} \mathrm{P}\right)$ values from Table 1 in the correlation equation for $\mathrm{Bu}_{3} \mathrm{P}$ additions to Michael acceptors in Fig. 6). (B) MAA values and electrophilicities $E$ for Michael acceptors $\mathbf{4 s} \mathbf{- 4 v}$

rehybridisations. ${ }^{17,18}$ Analogously, in this work the higher MAA for 1 than for equally reactive olefinic Michael acceptors ${ }^{15 a}$ (Fig. 7) along with the experimental kinetic data indicate that the main difference between $\mathbf{1}$ and Michael acceptors, such as 4, are the Marcus intrinsic barriers for the $\mathrm{R}_{3} \mathrm{P}$ addition at the differently hybridised electrophilic centres.

Even if the rate constants for the electrophile/ $\mathrm{R}_{3} \mathrm{P}$ additions are of the same order of magnitude, the MAA values show that allenoates 1 are considerably stronger Lewis acids than olefinic Michael acceptors or imines, such as 4t. As a consequence, the differences in the barriers for the retroadditions differentiate the two competing classes of electrophiles. Owing to their higher energetic barrier for retroaddition, only the allenic electrophiles 1 generate sufficiently high concentrations of reactive zwitterions, which are the pivotal intermediates for the subsequent ring-forming reactions. Thus, allenoates $\mathbf{1}$ are capable to compete with much stronger electrophiles. For example, 1f (MAA $=163 \mathrm{~kJ} \mathrm{~mol}^{-1}$ ) can be used as a partner for the more electrophilic yet less Lewis acidic $4 \mathbf{s}, \mathbf{4 t}$, or $4 \mathbf{u}$ in $\mathrm{Lu}$ cycloadditions. ${ }^{19-21}$ Benzylidenemalononitrile (4v) seems to be an exception. However, despite of its high MAA, 4v reacts reversibly with $\mathrm{Bu}_{3} \mathrm{P}$ and does not form an adduct with $\mathrm{Ph}_{3} \mathrm{P}$ $(\mathrm{ESI} \dagger)$. Yet, free $\mathbf{4 v}$ traps efficiently the zwitterion generated by $\mathrm{Ph}_{3} \mathrm{P}$ and $1 \mathrm{f}$ to yield cyclopentenes. ${ }^{22,23}$

The reactivities of allenic and olefinic Michael acceptors have been calibrated towards P-nucleophiles through determining the kinetics of their reactions with $\mathrm{Bu}_{3} \mathrm{P}$. Allenoates $\mathbf{1}$ are weaker electrofuges as well as weaker electrophiles than Michael acceptors $\mathbf{4}$ of similar Lewis acidity because of the higher intrinsic barriers for $\mathrm{sp} / \mathrm{sp}^{2}$ rehybridisation. The kinetic and thermodynamic data in this work will be instrumental for the design of novel $\mathrm{R}_{3} \mathrm{P}$-catalysed reactions with alkyl allenoates.

This work was funded by the Deutsche Forschungsgemeinschaft (DFG), project number 410831260, and the National Natural Science Foundation of China (NSFC) 21861132014.

\section{Conflicts of interest}

There are no conflicts to declare.

\section{Notes and references}

1 (a) C. Zhang and X. Lu, J. Org. Chem., 1995, 60, 2906; (b) X. Lu, C. Zhang and Z. Xu, Acc. Chem. Res., 2001, 34, 535; (c) Y. Wei and M. Shi, Org. Chem. Front., 2017, 4, 1876.

2 (a) Y. C. Fan and O. Kwon, in Lewis Base Catalysis in Organic Synthesis, ed. E. Vedejs and S. E. Denmark, Wiley-VCH, Weinheim (Germany), 1st edn, 2016, ch. 15, p. 715; (b) H. Guo, Y. C. Fan, Z. Sun, Y. Wu and O. Kwon, Chem. Rev., 2018, 118, 10049; (c) M. Shi, Y. Wei, M.-X. Zhao and J. Zhang, Organocatalytic Cycloadditions for Synthesis of Carboand Heterocycles, Wiley-VCH, Weinheim, 2018; (d) Y. Huang, J. Liao, W. Wang, H. Liu and H. Guo, Chem. Commun., 2020, 56, 15235; (e) Y. Wei and M. Shi, Chin. J. Chem., 2020, 38, 1395; $(f)$ C. Xie, A. J. Smaligo, X.-R. Song and O. Kwon, ACS Cent. Sci., 2021, 7, 536.

3 (a) Y. Liang, S. Liu, Y. Xia, Y. Li and Z.-X. Yu, Chem. - Eur. J., 2008, 14, 4361; (b) G.-T. Huang, T. Lankau and C.-H. Yu, J. Org. Chem., 2014, 79, 1700.

4 H. Mayr and M. Patz, Angew. Chem., Int. Ed. Engl., 1994, 33, 938.

5 (a) H. Mayr and A. R. Ofial, Pure Appl. Chem., 2005, 77, 1807; (b) H. Mayr, Angew. Chem., Int. Ed., 2011, 50, 3612.

6 (a) H. Mayr and A. R. Ofial, SAR QSAR Environ. Res., 2015, 26, 619; (b) H. Mayr, Tetrahedron, 2015, 71, 5095.

7 For a freely accessible database of $E, N$, and $s_{\mathrm{N}}$ parameters, see: https://www.cup.lmu.de/oc/mayr/DBintro.html.

8 S. Lakhdar, in Lewis Base Catalysis in Organic Synthesis, ed. E. Vedejs and S. E. Denmark, Wiley-VCH, Weinheim (Germany), 1st edn, 2016, ch. 4, p. 85.

9 B. J. Cowen and S. J. Miller, Chem. Soc. Rev., 2009, 38, 3102.

10 X.-Y. Wu, H.-Z. Gui, H. Jangra, Y. Wei, H. Zipse and M. Shi, Catal. Sci. Technol., 2020, 10, 3959.

11 A ratio of $k(\mathbf{1 a}) / k(\mathbf{1 f})=8$ was reported for the reactions with pyrrolidine (in $\mathrm{CHCl}_{3}$ ): C. Kiattisewee, A. Kaidad, C. Jiarpinitnun and T. Luanphaisarnnont, Monatsh. Chem., 2018, 149, 1059.

12 (a) R. J. Mayer, P. W. A. Allihn, N. Hampel, P. Mayer, S. A. Sieber and A. R. Ofial, Chem. Sci., 2021, 12, 4850; (b) P. M. Jüstel, A. Stan, C. D. Pignot and A. R. Ofial, Chem. - Eur. J., 2021, 27, 15928.

13 I. V. Alabugin, L. Kuhn, M. G. Medvedev, N. V. Krivoshchapov, V. A. Vil', I. A. Yaremenko, P. Mehaffy, M. Yarie, A. O. Terent'ev and M. A. Zolfigol, Chem. Soc. Rev., 2021, 50, 10253; 10700; and ref. cited therein.

14 (a) W. Yao, X. Dou, S. Wen, J. Wu, J. J. Vittal and Y. Lu, Nat. Commun., 2016, 7, 13024; (b) B. Mao, W. Shi, J. Liao, H. Liu, C. Zhang and H. Guo, Org. Lett., 2017, 19, 6340; (c) W. Shi, B. Mao, J. Xu, Q. Wang, W. Wang, Y. Wu, X. Li and H. Guo, Org. Lett., 2020, 22, 2675; 6600.

15 (a) D. S. Allgäuer, H. Jangra, H. Asahara, Z. Li, Q. Chen, H. Zipse, A. R. Ofial and H. Mayr, J. Am. Chem. Soc., 2017, 139, 13318; (b) A. Mood, M. Tavakoli, E. Gutman, D. Kadish, P. Baldi and D. L. Van Vranken, J. Org. Chem., 2020, 85, 4096.

16 B. Kempf and H. Mayr, Chem. - Eur. J., 2005, 11, 917.

17 P. A. Byrne, S. Kobayashi, E.-U. Würthwein, J. Ammer and H. Mayr, J. Am. Chem. Soc., 2017, 139, 1499.

18 (a) R. A. Marcus, J. Phys. Chem., 1968, 72, 891; (b) W. J. Albery, Annu. Rev. Phys. Chem., 1980, 31, 227.

19 Q. Zhao, X. Han, Y. Wei, M. Shi and Y. Lu, Chem. Commun., 2012, 48, 970-972.

20 X.-F. Zhu, J. Lan and O. Kwon, J. Am. Chem. Soc., 2003, 125, 4716.

21 L. Birbaum, L. Gillard, H. Gerard, H. Oulyadi, G. Vincent, X. Moreau, M. De Paolis and I. Chataigner, Chem. - Eur. J., 2019, 25, 13688.

$22 \mathrm{X} . \mathrm{Lu}, \mathrm{Z}$. Lu and X. Zhang, Tetrahedron, 2006, 62, 457.

23 For $[4+2]$ cycloadditions of $4 \mathbf{v}$ with $1 \mathbf{i}$ and $\mathbf{1 j}$, see: Y. S. Tran and O. Kwon, J. Am. Chem. Soc., 2007, 129, 12632. 